\title{
Deletion of the gene encoding the islet-specific glucose-6-phosphatase catalytic subunit-related protein autoantigen results in a mild metabolic phenotype
}

\author{
Y. Wang • C. C. Martin • J. K. Oeser • S. Sarkar • \\ O. P. McGuinness • J. C. Hutton • R. M. O’Brien
}

Received: 27 July 2006 / Accepted: 24 October 2006 / Published online: 31 January 2007

(C) Springer-Verlag 2007

\begin{abstract}
Aims/hypothesis Islet-specific glucose-6-phosphatase catalytic subunit-related protein (IGRP, now known as glucose6-phosphatase, catalytic, 2 [G6PC2]) has recently been identified as a major autoantigen in mouse and human type 1 diabetes. Strategies designed to suppress expression of the gene encoding G6PC2 might therefore be useful in delaying or preventing the onset of this disease. However, since the function of G6PC2 is unclear, the concern with such an approach is that a change in G6PC2 expression might itself have deleterious consequences.

Methods To address this concern and assess the physiological function of G6PC2, we generated G6pc2-null mice and performed a phenotypic analysis focusing principally on energy metabolism.

Results No differences in body weight were observed and no gross anatomical or behavioural changes were evident. In 16-week-old animals, following a 6-h fast, a small but significant decrease in blood glucose was observed in both male $(-14 \%)$ and female $(-11 \%) G 6 p c 2^{-/}$mice, while female $\mathrm{G}_{\mathrm{f}} \mathrm{pc} 2^{-/-}$mice also exhibited a $12 \%$ decrease in
\end{abstract}

Electronic supplementary material Supplementary material is available in the online version of this article at http://dx.doi.org/ 10.1007/s00125-006-0564-1 and is accessible to authorised users.

Y. Wang • C. C. Martin · J. K. Oeser · O. P. McGuinness •

R. M. O'Brien $(\square)$

Department of Molecular Physiology and Biophysics,

Vanderbilt University Medical School,

761 PRB,

Nashville, TN 37232-0615, USA

e-mail: richard.obrien@vanderbilt.edu

S. Sarkar · J. C. Hutton

Barbara Davis Center for Childhood Diabetes,

University of Colorado Health Sciences Center,

Aurora, CO, USA plasma triacylglycerol. Plasma cholesterol, glycerol, insulin and glucagon concentrations were unchanged.

Conclusions/interpretation These results argue against the possibility of G6PC2 playing a major role in pancreatic islet stimulus secretion coupling or energy homeostasis under physiological conditions imposed by conventional animal housing. This indicates that manipulating the expression of $G 6 P C 2$ for therapeutic ends may be feasible.

Keywords Autoantigen - Glucose ·

Glucose-6-phosphatase $\cdot$ Insulin $\cdot$ Islet $\cdot$ Mouse

\section{Abbreviations \\ G6P glucose 6-phosphate \\ G6PC glucose-6-phosphatase catalytic subunit \\ G6PC2 glucose-6-phosphatase, catalytic, 2 \\ NOD non-obese diabetic}

\section{Introduction}

In liver, glucose-6-phosphatase catalyses the hydrolysis of glucose 6-phosphate (G6P) to glucose and inorganic phosphate, the final step in the gluconeogenic and glycogenolytic pathways. Mutations within the glucose-6phosphatase catalytic subunit (G6Pase, now known as G6PC) cause glycogen storage disease type 1a, which is primarily characterised by severe hypoglycaemia in the post-absorptive state. Although glucose-6-phosphatase activity and $G 6 P C$ mRNA are detectable in islets, the activity displays distinct kinetic behaviour and inhibitor profiles compared with that assayed in hepatic extracts, an observation that might be explained by the existence of a 
distinct G6PC isoform in islets, present in addition to the known G6PC isoform [1]. Indeed, we have previously identified an islet-specific G6PC-related protein (IGRP, now known as glucose-6-phosphatase, catalytic, 2 [G6PC2]) that is produced specifically in islet beta cells [1]. However, the biological function of G6PC2 is unclear. Overproduction of G6PC2 by transient transfection of cell lines has been reported to have little [2] or no [1] effect on G6P hydrolysis in tissue homogenates. Questions thus arise as to whether the physiologically important substrate that G6PC2 hydrolyses is something other than G6P or whether a low rate of G6P hydrolysis by G6PC2 might nevertheless influence glucose-stimulated insulin secretion in vivo.

Although the role of G6PC2 in beta cell function remains unclear, G6PC2 was recently identified as a major autoantigen in the non-obese diabetic (NOD) mouse model of type 1 diabetes [3]. In NOD mice up to $40 \%$ of the CD8-positive cells infiltrating the islet were found to be G6PC2-reactive [3]. Subsequent reports have shown that G6PC2 is also recognised by CD4-positive T cells [4]. Most importantly, G6PC2 has recently also been shown to be an autoantigen in human type 1 diabetes [5] and in humanised NOD mice [6]. Given the observations that administration of G6PC2derived peptides abrogate or delay the disease process in NOD mice $[4,7]$ and that NOD mice expressing a nonantigenic form of insulin do not develop diabetes [8], it is possible that strategies designed to suppress $G 6 p c 2$ expression might also be used to delay or prevent the onset of this disease. However, since the function of G6PC2 is unclear, the concern with such an approach is that the absence of G6PC2 might itself have deleterious consequences. To address this concern and gain insight into the biological function of G6PC2 we have characterised the phenotype of mice containing a global knockout of the $G 6 p c 2$ gene.

\section{Materials and methods}

For details of animal care, generation of the $G 6 p c 2$ targeting vector, generation of $G 6 p c 2$ knockout mice, and $G 6 p c 2$ mRNA expression analyses and immunohistochemical staining see the Electronic supplementary material (ESM).

Phenotypic analysis of G6pc2 knockout mice Animals were fasted for $5 \mathrm{~h}$, weighed and then anaesthetised $1 \mathrm{~h}$ later using isoflurane before isolation of blood samples $(\sim 200 \mu \mathrm{l})$ from the retro-orbital venous plexus.

Whole-blood glucose concentrations were determined using a monitor (Accu-Check Advantage; Roche, Indianapolis, USA). EDTA $(5 \mu \mathrm{l} ; 0.5 \mathrm{~mol} / \mathrm{l})$ was then added before centrifugation to isolate plasma. Trasylol (aprotinin; $5 \mu \mathrm{l}$; Bayer Health Care, West Haven, CT, USA) was added to the plasma to prevent proteolysis of glucagon. Cholesterol was assayed using a cholesterol reagent kit (Raichem, San Diego, CA, USA), while triacylglycerol and glycerol were assayed using a serum triacylglycerol determination kit (Sigma, St Louis, MO, USA). Insulin and glucagon levels were quantitated using radioimmunoassays by the Vanderbilt Diabetes Center Hormone Assay Core.

Hyperglycaemic clamps on 5-h fasted chronically catheterised conscious male mice were performed by the Vanderbilt Mouse Metabolic Phenotyping Center as previously described [9].

Statistical analyses Data were analysed using a Student's $t$ test: two sample assuming equal variance. The level of significance was as indicated (two-sided test).

\section{Results}

A modified mouse G6pc2 allele, in which the coding sequence of exons 1 to 3 plus $10 \mathrm{bp}$ of the third intron [1] were replaced by a LacZ/Neo cassette, was created by genetargeting in $129 / \mathrm{SvEv}^{\mathrm{Brd}}$ (Lex-1) embryonic stem cells (Fig. 1a). Correct gene-targeting was confirmed by Southern blot (Fig. 1b) and PCR (data not shown) analysis before injection of embryonic stem cells into C57BL/6 (albino) blastocysts and subsequent generation of $G 6 p c 2^{-1+}$ mice on a mixed $129 / \mathrm{SvEv}^{\mathrm{Brd}} \times \mathrm{C} 57 \mathrm{BL} / 6$ background.

Genotype analysis of 234 3-week-old pups generated by cross-breeding heterozygous $G 6 P C 2^{-/+}$mice demonstrated that 68 mice were $G 6 p c 2^{+/+}, 108$ were $G 6 p c 2^{-/+}$, and 58 were $G 6 p c 2^{-1-}$, a distribution close to the expected pattern for Mendelian inheritance. The ratio of male to female mice was 123:111. Cross-breeding experiments revealed that both male and female homozygous $G 6 p c 2^{-/-}$mice are fertile.

Biochemical analyses confirmed that the $G 6 p c 2$ gene was not expressed in $G 6 p c 2^{-/-}$mice. Thus, RNA blotting demonstrated the absence of G6pc2 mRNA (Fig. 1c) and immunohistochemical staining of pancreas tissue showed the loss of G6PC2 immunoreactivity (Fig. 1d) in $G 6 p c 2^{-/-}$ mice. The size and number of islets in knockout animals were indistinguishable from wild-type as were the relative numbers of alpha and beta cells (data not shown).

The activity and behaviour of $G 6 p c 2^{-/-}$mice were indistinguishable from their wild-type and heterozygous littermates at all ages, from birth up to 1 year in age. No gross anatomical changes were observed either externally or to major internal organs and no differences were seen in the weights or lengths of $G 6 p c 2^{-/-}$and wild-type mice (Table 1).

Table 1 summarises changes in metabolic parameters in these animals assayed at 16 weeks of age following a 6-h 

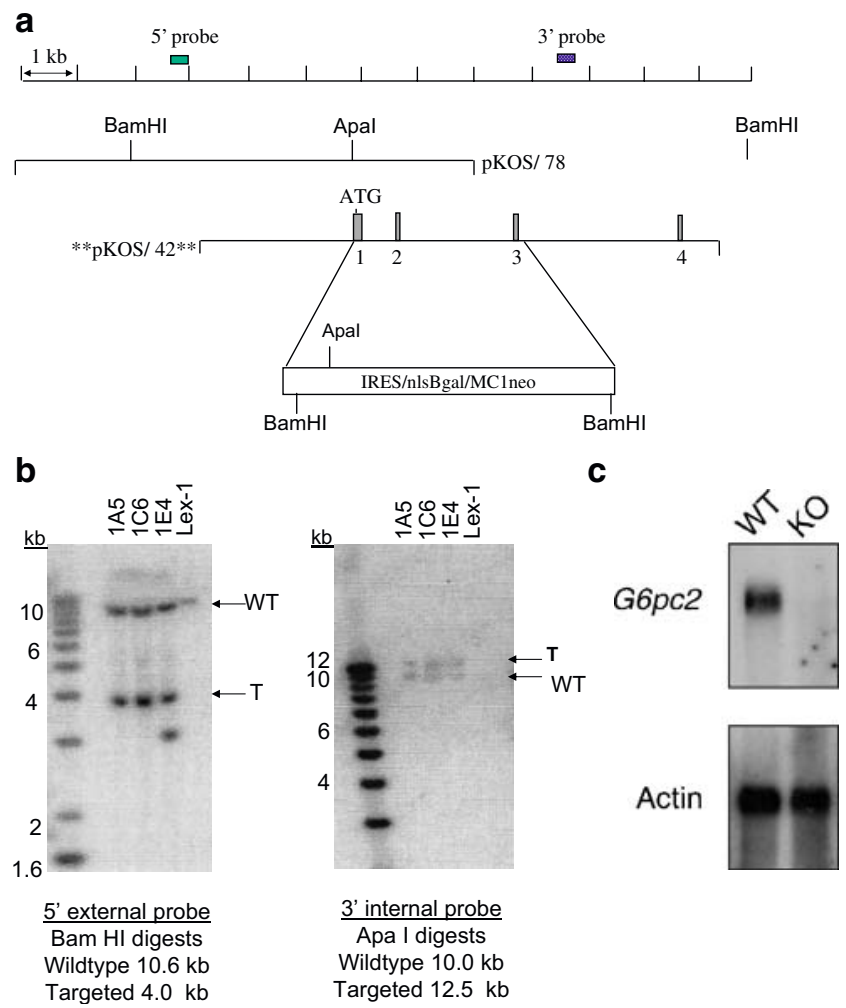

d
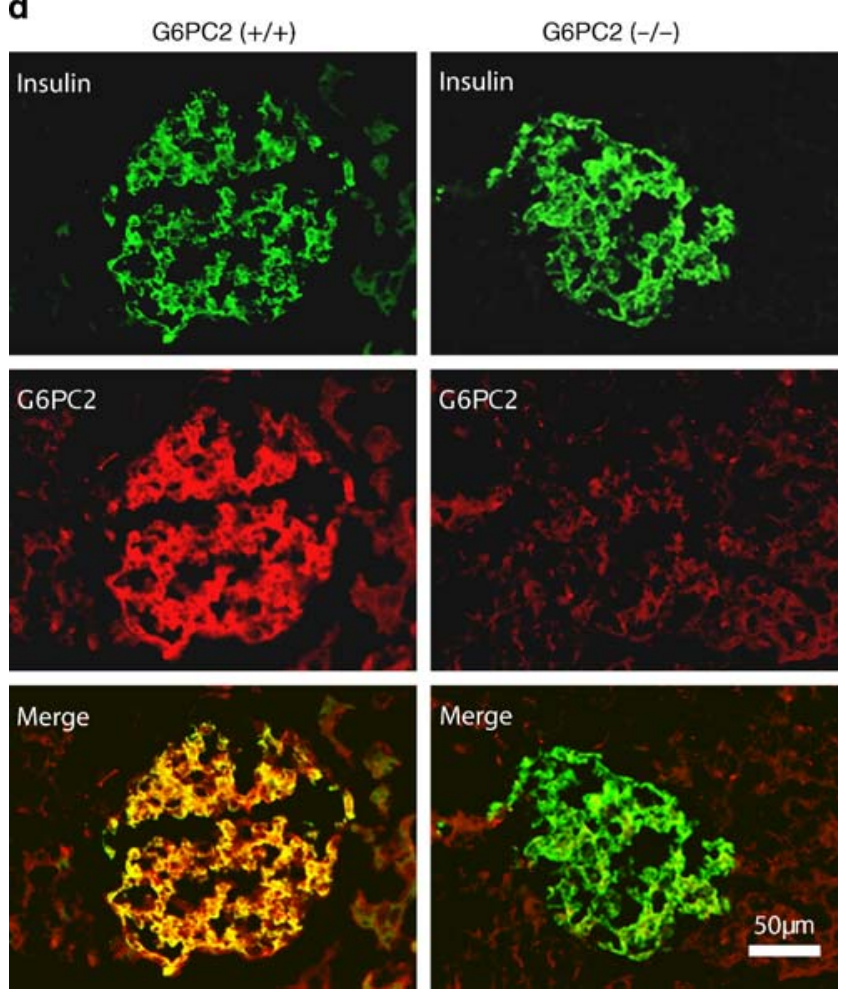

fast. In both male and female $G 6 p c 2^{-/-}$mice there was a statistically significant 14 and $11 \%$ decrease, respectively, in blood glucose in comparison with wild-type mice (Table 1). The blood glucose level in male $G 6 p c 2^{-/-}$mice
Fig. 1 Generation and authentication of $G 6 p c 2$ knockout mice. a Strategy used to generate $G 6 p c 2$ knockout mice by homologous recombination in embryonic stem cells. A schematic representation of the wild-type murine $G 6 p c 2$ locus and the targeting construct are shown. IRES, internal ribosome entry site; $n l s$, nuclear localisation signal; Bgal, beta galactosidase; MClneo, originally the name given to describe a DNA fragment that contains a modified TK promoter driving neomycin (neo) gene expression. b Southern blot analysis of the $G 6 p c 2$ locus using genomic DNA extracted from three targeted embryonic stem cell lines, or wild-type embryonic stem cell genomic DNA, designated Lex-1, as a control, using the $5^{\prime}$ and $3^{\prime}$ diagnostic probes (see a). The sizes of the wild-type (WT) locus and targeted (T) alleles and the location of DNA size markers are indicated. c Analysis of mouse G6pc2 mRNA expression by RNA blotting. d Immunohistochemical staining of wild-type and $G 6 p c 2$ knockout mouse pancreas with antisera raised to insulin and G6PC2

was also lower than that in male $G 6 p c 2^{-/+}$mice (Table 1). In female $G 6 p c 2^{-/-}$mice there was also a statistically significant $12 \%$ decrease in plasma triacylglycerol (Table 1). There were no statistically significant differences in plasma cholesterol, glycerol, insulin and glucagon concentrations between $G 6 p c 2^{-/-}$and wild-type mice (Table 1). G6pc2 $2^{-/-}$ mice showed sex-related variation in the majority of these metabolic parameters that were in the same direction and of similar magnitude to the sex-related differences in wildtype mice. Thus, in males versus females, insulin, triacylglycerol, cholesterol and glucose tended to be higher whereas glucagon was lower.

Since some metabolic disturbances, such as the development of diabetes in NOD mice, only arise in older animals, several metabolic parameters were re-assayed in 6-h fasted female mice at a later time point. The mean ages of the $G 6 p c 2^{+/+}, G 6 p c 2^{-/+}$and $G 6 p c 2^{-/-}$animals studied were 52, 48 and 54 weeks, respectively. As seen in 16-week-old mice, there was a trend towards lowered blood glucose in these older $G 6 p c 2^{-/-}$mice, although less animals were analysed than at 16 weeks and the difference did not reach statistical significance (ESM Table 1). However, a statistically significant $19 \%$ decrease in plasma triacylglycerol was again apparent (ESM Table 1). These data suggest that a severe metabolic phenotype does not arise in older animals.

Similarly, some metabolic disturbances only become readily apparent under stimulatory rather than basal conditions. Hyperglycaemic clamps were therefore used to provide a measure of dynamic islet function in vivo. Blood glucose was raised to $\sim 14 \mathrm{mmol} / 1$ and insulin secretion was assessed over a 120-min period (Fig. 2). Glucose requirements were comparable: $45 \pm 2$ vs $39 \pm 2 \mathrm{mg} \mathrm{kg}^{-1} \mathrm{~min}^{-1}$ in $G 6 p c 2^{-1-}$ vs wild-type. The data show no difference in insulin secretion between wild-type and $G 6 p c 2^{-/-}$mice (Fig. 2). This suggests that the absence of G6PC2 affects fasting but not maximal glucose-stimulated insulin secretion, and is consistent with the conclusion that the absence of $\mathrm{G} 6 \mathrm{PC} 2$ results in a mild metabolic phenotype. 
Table 1 Phenotypic characterisation of G6pc2 knockout mice

\begin{tabular}{|c|c|c|c|c|c|c|c|c|}
\hline $\begin{array}{l}\text { Sex and } \\
\text { genotype }\end{array}$ & $\begin{array}{l}\text { Weight } \\
\text { (g) }\end{array}$ & $\begin{array}{l}\text { Length } \\
(\mathrm{mm})\end{array}$ & $\begin{array}{l}\text { Glucose } \\
(\mathrm{mmol} / \mathrm{l})\end{array}$ & $\begin{array}{l}\text { Cholesterol } \\
(\mathrm{mmol} / \mathrm{l})\end{array}$ & $\begin{array}{l}\text { Triacylglycerol } \\
(\mathrm{mmol} / \mathrm{l})\end{array}$ & $\begin{array}{l}\text { Glycerol } \\
(\mathrm{mmol} / \mathrm{l})\end{array}$ & $\begin{array}{l}\text { Insulin } \\
\text { (pmol/1) }\end{array}$ & $\begin{array}{l}\text { Glucagon } \\
\text { (ng/l) }\end{array}$ \\
\hline Female WT & $\begin{array}{l}22.1 \pm 0.4 \\
(24)\end{array}$ & $\begin{array}{l}97.8 \pm 0.7 \\
(24)\end{array}$ & $6.84 \pm 0.28$ & $\begin{array}{l}1.58 \pm 0.05 \\
(23)\end{array}$ & $\begin{array}{l}0.51 \pm 0.02 \\
(23)\end{array}$ & $\begin{array}{l}0.31 \pm 0.02 \\
(23)\end{array}$ & $70 \pm 8(17)$ & $\begin{array}{l}55.0 \pm 9.3 \\
(13)\end{array}$ \\
\hline Female $^{-/+}$ & $\begin{array}{l}21.6 \pm 0.4 \\
(27)\end{array}$ & $\begin{array}{l}97.7 \pm 0.6 \\
(27)\end{array}$ & $6.51 \pm 0.19(27)$ & $\begin{array}{l}1.64 \pm 0.06 \\
(26)\end{array}$ & $\begin{array}{l}0.46 \pm 0.02 \\
(26)\end{array}$ & $\begin{array}{l}0.29 \pm 0.01 \\
(26)\end{array}$ & $55 \pm 5(17)$ & $\begin{array}{l}62.1 \pm 8.5 \\
(16)\end{array}$ \\
\hline Female KO & $\begin{array}{l}21.1 \pm 0.5 \\
(23)\end{array}$ & $\begin{array}{l}97.9 \pm 0.5 \\
(23)\end{array}$ & $\begin{array}{l}6.12 \pm 0.24 \\
(23) *\end{array}$ & $\begin{array}{l}1.55 \pm 0.05 \\
(22)\end{array}$ & $\begin{array}{l}0.44 \pm 0.02 \\
(22) * * * *\end{array}$ & $\begin{array}{l}0.28 \pm 0.02 \\
(22)\end{array}$ & $70 \pm 12(15)$ & $\begin{array}{l}58.6 \pm 5.8 \\
(13)\end{array}$ \\
\hline Male WT & $\begin{array}{l}27.7 \pm 0.6 \\
(20)\end{array}$ & $\begin{array}{l}102.6 \pm 0.7 \\
(20)\end{array}$ & $7.32 \pm 0.15(20)$ & $\begin{array}{l}1.90 \pm 0.08 \\
(19)\end{array}$ & $\begin{array}{l}0.55 \pm 0.03 \\
(19)\end{array}$ & $\begin{array}{l}0.26 \pm 0.01 \\
(19)\end{array}$ & $102 \pm 17(15)$ & $\begin{array}{l}33.4 \pm 4.6 \\
(14)\end{array}$ \\
\hline $\mathrm{Male}^{-/+}$ & $\begin{array}{l}28.1 \pm 0.5 \\
(39)\end{array}$ & $\begin{array}{l}102.6 \pm 0.5 \\
(39)\end{array}$ & $6.94 \pm 0.18$ (39) & $\begin{array}{l}1.93 \pm 0.05 \\
(36)\end{array}$ & $\begin{array}{l}0.61 \pm 0.02 \\
(36)\end{array}$ & $\begin{array}{l}0.27 \pm 0.01 \\
(36)\end{array}$ & $82 \pm 7(25)$ & $\begin{array}{l}33.7 \pm 2.9 \\
(21)\end{array}$ \\
\hline Male KO & $\begin{array}{l}27.0 \pm 0.5 \\
(29)\end{array}$ & $\begin{array}{l}101.2 \pm 0.5 \\
(29)\end{array}$ & $\begin{array}{l}6.27 \pm 0.17(28) \\
* * *, * *\end{array}$ & $\begin{array}{l}1.81 \pm 0.05 \\
(28)\end{array}$ & $\begin{array}{l}0.62 \pm 0.03 \\
(28)\end{array}$ & $\begin{array}{l}0.27 \pm 0.02 \\
(28)\end{array}$ & $88 \pm 15(17)$ & $\begin{array}{l}39.7 \pm 4.6 \\
(16)\end{array}$ \\
\hline
\end{tabular}

At 16 weeks of age mice were fasted for $5 \mathrm{~h}$ and then weighed. One hour later mice were anaesthetised, their length measured and blood samples taken. Blood glucose and plasma cholesterol, triacylglycerol, glycerol, insulin and glucagon levels were determined as described in Materials and methods.

Results represent mean data \pm SEM obtained from the indicated number of animals in parentheses

Glucose: $* * * p<0.0001$ for male WT vs Male $\mathrm{KO} ; * * p<0.01$ for male KO vs male heterozygous; $* p=0.05$ for female WT vs female KO,

Triacylglycerol: $* * * * p<0.05$ for female WT vs female KO

$W T$ wild-type; $K O$ knockout

\section{Discussion}

The data presented indicate that deletion of the G6pc2 gene results in a mild metabolic phenotype on a mixed $129 \mathrm{SvEv}^{\mathrm{Brd}} \times \mathrm{C} 57 \mathrm{BL} / 6$ background. This bodes well for future studies in which $G 6 p c 2^{-1-}$ mice are bred on to diabetes-susceptible strains such as the NOD mouse. Based on present evidence, ablation of the gene may actually enhance islet responsiveness at fasting glucose concentrations, which would be an advantage in the face of reduced beta cell mass. Thus, unlike the case of other autoantigens

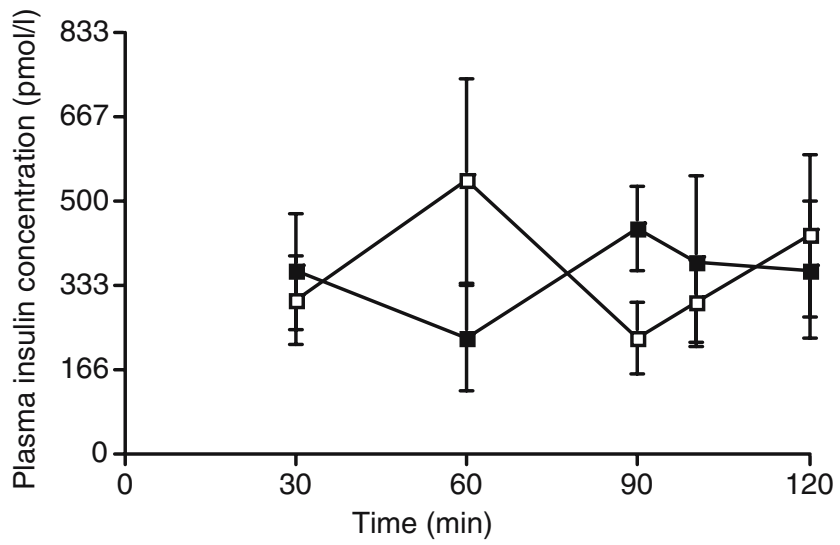

Fig. 2 Assessment of insulin secretion in G6pc2 knockout mice in vivo using hyperglycaemic clamps. Hyperglycaemic clamps were performed in 5-h fasted chronically catheterised conscious male wildtype (closed symbols) and G6pc2 knockout (open symbols) mice as described in Materials and methods. Results show the mean insulin concentrations \pm SEM in three wild-type (mean age 35 weeks) and four $G 6 p c 2$ knockout (mean age 32 weeks) animals such as insulin [8], the physiological consequences of $G 6 p c 2$ gene ablation appear to be tolerable.

The data derived from fasting mice are consistent with G6P being a substrate for G6PC2 in vivo since removal of G6PC2 would leave the action of glucokinase unopposed and would in effect be equivalent to an increase in glucokinase activity. Future experiments will directly address the hypothesis that the observed decrease in fasting blood glucose in $G 6 p c 2$ knockout mice is a consequence of altered kinetics of glucose-stimulated insulin secretion. However, the hyperglycaemic clamp data suggest that maximal glucose-stimulated insulin secretion is unaltered (Fig. 2). Interestingly, Matchinsky et al. [10] concluded that, while normal rat islets do contain measurable glucose6-phosphatase activity, this does not play a role in glucose metabolism and sensing by the normal beta cell. Since rat islets do not produce G6PC2 [1] it will be of interest to repeat this analysis using mouse islets.

Acknowledgements We thank P. Jacobson, D. Powell, C. Pettepher, H. Chen, K. Platt and K. Rufus for assistance with this project. We also thank W. Snead, A. Slater and B. Trivedi for performing insulin and glucagon assays. Research in the laboratory of R. O'Brien was supported by NIH grants DK061645 and DK076027. Research in the laboratory of J. C. Hutton was supported by the American Diabetes Association (9901-116), NIH grant DK076027 and the Barbara Davis Center Diabetes and Endocrinology Research Center (P30 DK57516). Research in the laboratory of O. P. McGuinness was supported by NIH grant DK064877. The Vanderbilt Hormone Assay \& Analytical Services Core is supported by NIH grant P60 DK20593 to the Vanderbilt Diabetes Research Training Center (VDRTC), and by NIH grant DK59637 to the Vanderbilt Mouse Metabolic Phenotyping 
Center. The Vanderbilt Cancer Center/Diabetes Research and Training Center Transgenic Animal/Embryonic Stem Cell Core Facility is funded by NIH grant P60 DK20593-24 (to the VDRTC) and NIH grant P30 CA68485-06 (to the Vanderbilt-Ingram Cancer Center).

Duality of interest The authors have no financial interests that would result in a conflict of interest with regard to this work.

\section{References}

1. Martin CC, Bischof LJ, Bergman B et al (2001) Cloning and characterization of the human and rat islet-specific glucose-6phosphatase catalytic subunit-related protein (IGRP) genes. J Biol Chem 276:25197-25207

2. Petrolonis AJ, Yang Q, Tummino PJ et al (2004) Enzymatic characterization of the pancreatic islet-specific glucose-6phosphatase-related protein (IGRP). J Biol Chem 279:1397613983

3. Lieberman SM, Evans AM, Han B et al (2003) Identification of the beta cell antigen targeted by a prevalent population of pathogenic CD8 $+\mathrm{T}$ cells in autoimmune diabetes. Proc Natl Acad Sci USA 100:8384-8388
4. Mukherjee R, Wagar D, Stephens TA, Lee-Chan E, Singh B (2005) Identification of CD4+ T cell-specific epitopes of isletspecific glucose-6-phosphatase catalytic subunit-related protein: a novel beta cell autoantigen in type 1 diabetes. J Immunol 174:5306-5315

5. Yang J, Danke NA, Berger D et al (2006) Islet-specific glucose-6phosphatase catalytic subunit-related protein-reactive CD4+ T cells in human subjects. J Immunol 176:2781-2789

6. Takaki T, Marron MP, Mathews CE et al (2006) HLA-A*0201restricted T cells from humanized NOD mice recognize autoantigens of potential clinical relevance to type 1 diabetes. J Immunol 176:3257-3265

7. Han B, Serra P, Amrani A et al (2005) Prevention of diabetes by manipulation of anti-IGRP autoimmunity: high efficiency of a low-affinity peptide. Nat Med 11:645-652

8. Nakayama M, Abiru N, Moriyama H et al (2005) Prime role for an insulin epitope in the development of type 1 diabetes in NOD mice. Nature 435:220-223

9. Niswender KD, Shiota M, Postic C, Cherrington AD, Magnuson MA (1997) Effects of increased glucokinase gene copy number on glucose homeostasis and hepatic glucose metabolism. J Biol Chem 272:22570-22575

10. Sweet IR, Najafi H, Li G, Grodberg J, Matschinsky FM (1997) Measurement and modeling of glucose-6-phosphatase in pancreatic islets. Am J Physiol 272:E696-E711 